\title{
Epidermal growth factor receptor gene mutation status and its association with clinical characteristics and tumor markers in non-small-cell lung cancer patients in Northwest China
}

\author{
ABLAJAN ABDURAHMAN ${ }^{1}$, JURAT ANWAR ${ }^{1}$, ABDUGHENI TURGHUN ${ }^{1}$, \\ MADINIYET NIYAZ ${ }^{2}$, LIWEI ZHANG ${ }^{1}$ and IDIRIS AWUT ${ }^{1}$ \\ ${ }^{1}$ Department of Thoracic Surgery, ${ }^{2}$ Clinical Research Institute, \\ First Affiliated Hospital of Xinjiang Medical University, Urumqi, Xinjiang 830054, P.R. China
}

Received January 16, 2015; Accepted March 24, 2015

DOI: $10.3892 / \mathrm{mco} .2015 .564$

\begin{abstract}
This study was conducted to investigate the mutation status of epidermal growth factor receptor (EGFR) and its association with clinical characteristics and tumor markers in non-small-cell lung cancer (NSCLC) patients from the Xinjiang Uygur Autonomous Region in China. We enrolled 51 cases of NSCLC patients who received radical surgical treatment in the First Affiliated Hospital of Xinjiang Medical University. Quantitative polymerase chain reaction was applied to detect exons 18, 19, 20 and 21 of the EGFR gene in tumor tissues. Multiple tumor markers, including carcinoembryonic antigen (CEA), were assessed preoperatively. The EGFR-positive rate was $49.02 \%(25 / 51)$, with a mutation rate of $8 \%(2 / 25)$ in exon $18,52 \%(13 / 51)$ in exon $19,40 \%(10 / 51)$ in exon 21 and no mutations in exon 20 . The positive mutation rate in men and women was $37.5 \%$ (12/32) and $68.42 \%$, respectively (13/19), with a statistically significantly higher rate in women $(\mathrm{P}<0.05)$. There were also statistically significant differences among adenocarcinoma, adenosquamous carcinoma and squamous cell carcinoma cases $(\mathrm{P}<0.05)$, while no statistically significant differences were observed in adenocarcinoma cases regarding degree of differentiation, lymph node metastasis and TNM stage $(\mathrm{P}>0.05)$. There was a statistically
\end{abstract}

Correspondence to: Professor Idiris Awut or Professor Liwei Zhang, Department of Thoracic Surgery, First Affiliated Hospital of Xinjiang Medical University, 137 Liyushan South Road, Urumqi, Xinjiang 830054, P.R. China

E-mail: edrs5@yahoo.com

E-mail: zhangliwei@medmail.com.cn

Abbreviations: NSCLC, non-small-cell lung cancer; EGFR, epidermal growth factor receptor; CEA, carcinoembryonic antigen; CA125, carbohydrate antigen 125; CA199, carbohydrate antigen 199; CYFRA 21-1, cytokeratin-19-fragment; SCC, squamous cell carcinoma; ProGRP, progastrin-releasing peptide; AFP, $\alpha$-fetoprotein

Key words: Xinjiang, non-small-cell lung cancer, epidermal growth factor receptor, targeted therapy, tumor marker significant association between the EGFR gene mutation status and the preoperative serum CEA level $(\mathrm{P}<0.05)$. The mutation rate of the EGFR gene was $68.42 \%$ in female lung adenocarcinoma patients, which supports the application of targeted therapy in such cases. However, whether it is possible to obtain information regarding targeted therapy through measuring the level of serum CEA for NSCLC patients with unknown EGFR mutation status requires further investigation through related studies including a higher number of cases.

\section{Introduction}

Lung cancer is one of the most common malignant tumors in humans, with an equally high incidence in men and in women. Approximately $80 \%$ of lung cancer cases are non-small-cell lung cancer (NSCLC) (1). The majority of the patients present with advanced-stage lung cancer at diagnosis, when radical excision is no longer feasible (2) and the remaining treatment options include radiotherapy, chemotherapy and immune therapy. The rate of response to radiotherapy and chemotherapy is only $15-35 \%$, which may not effectively improve the survival rate and life quality of the patients. Therefore, the total 5-year survival rate of lung cancer patients is only $\sim 15 \%$ (2-4).

Over the last few years, genetic testing and targeted therapy based on epidermal growth factor receptor (EGFR) gene mutation status has attracted significant attention. Multiple clinical studies indicated that tyrosine kinase inhibitors (TKIs) have effectively extended the survival time and improved the life quality of NSCLC patients (5), with a total effectiveness rate of $>70 \%$. However, the effectiveness rate of TKI treatment for wild-type EGFR cancers is only $10-15 \%$ (6). Therefore, it is crucial to determine the mutation status of the EGFR gene in NSCLC patients prior to TKI treatment $(6,7)$.

Tumor markers are specific molecules produced and released by tumor cells and they may be present in the tissues, body fluids and excreta of cancer patients. Tumor markers are mainly used in clinical practice to locate the primary tumor, screen high-risk populations, identify and diagnose benign and malignant tumors, determine tumor development, observe and evaluate the efficacy of tumor treatment and predict the 
prognosis and recurrence of the tumor (8-10). The number of studies investigating the association of tumor markers with the EGFR gene is currently limited. In this study, multiple tumor markers were assessed preoperatively in patients with known EGFR gene mutations, to determine whether there is a correlation between EGFR mutation status and tumor markers.

Quantitative polymerase chain reaction (qPCR) was used to detect mutations of the EGFR gene in NSCLC patients who received radical surgery in our hospital and the association of mutation status with clinicopathological characteristics and tumor markers was investigated, in order to establish a pathological basis for individual targeted therapy of postoperative NSCLC patients in Xinjiang.

\section{Patients and methods}

Patients. A total of 51 NSCLC patients who received radical surgery at the Department of Thoracic Surgery of the First Affiliated Hospital of Xinjiang Medical University between April, 2013 and July, 2014, were included in this study. The patients included 32 men and 19 women (male:female ratio, 1.68:1). None of the patients underwent radiotherapy, chemotherapy or other specialized therapy preoperatively and they all signed a consent form regarding the collection of samples from surgical tumor tissues.

Tumor histology and stage. There were 40 cases of adenocarcinoma, 7 of squamous cell carcinoma (SCC), 3 of adenosquamous carcinoma and 1 case of carcinoid tumor. As regards the degree of differentiation, 6 of the cases were well-differentiated, 28 were moderately differentiated and 17 were poorly differentiated. A total of 23 cases presented with lymph node metastasis. As regards postoperative pathological classification, 12 patients had stage IA, 8 had stage IB, 6 had stage IIA, 6 had stage IIB, 16 had stage IIIA, 2 had stage IIIB and 1 had stage IV disease.

Tumor marker determination. Tumor markers, including cytokeratin-19-fragment (CYFRA21-1), carbohydrate antigen 125 (CA125) and carbohydrate antigen 19-9 (CA19-9), SCC antigen, carcinoembryonic antigen (CEA), progastrin-releasing peptide (ProGRP) and $\alpha$-fetoprotein (AFP) were measured preoperatively in the serum of all the patients.

Fasting blood was collected for analysis. CA125, CA19-9 and CEA were determined by the direct chemiluminescence method using an AFP determination kit [Siemens Healthcare Diagnostics (Shanghai) Co. Ltd., Shanghai, China]. CYFRA 21-1, SCC and ProGRP were determined by chemiluminescence particles immunoassays using the ARCHITECT CYFRA 21-1 Reagent kit [Abbott Laboratories Trading (Shanghai) Co., Ltd. Shanghai, China]. The results were interpreted as follows: CYFRA 21-1, negative $\leq 2.08$ and positive $>2.08 \mathrm{ng} / \mathrm{ml}$; CA19-9, negative $\leq 37$ and positive $>37 \mathrm{U} / \mathrm{ml}$; CA125, negative $\leq 32.4$ and positive $>32.4 \mathrm{U} / \mathrm{ml}$; SCC antigen, negative $\leq 5 \mathrm{ng} / \mathrm{ml}$ and positive $>5 \mathrm{ng} / \mathrm{ml}$; AFP, negative $\leq 8.1$ and positive $>8.1 \mathrm{ng} / \mathrm{ml}$; and ProGRP, negative $\leq 63 \mathrm{pg} / \mathrm{ml}$ and positive $>63 \mathrm{pg} / \mathrm{ml}$.

DNA extraction. The test samples were paraffin-coated tumor tissues. A total of $8-10$ sections $(8 \mu \mathrm{m})$ were placed in a 1.5-ml EP tube. DNA was extracted according to the instructions manual of the QIAamp DNA FFPE Tissue kit (Qiagen, Hilden, Germany). The concentration and purity of the DNA were determined with a NanoDrop 2000 spectrophotometer (Thermo Fisher Scientific, Ottawa, ON, Canada). The OD260/OD280 ratio of the DNA sample was $1.8 \pm 0.2$ and the OD260/OD230 ratio was $\geq 1.7$; the concentration was $20-50 \mathrm{ng} / \mu 1$.

$q P C R$. A probe that specifically recognizes the mutated EGFR and reference genes was designed. Fluorescence released by the probe was detected by qPCR. The gene mutation status was then determined. Mutations in exons 18, 19, 20 and 21 of the EGFR gene were qualitatively tested by the Human EGFR Gene Mutation Detection kit (Beijing ACCB Biotech Ltd., Beijing, China). There were positive and negative controls for every measurement. The reaction was usually completed within $1.5 \mathrm{~h}$. The results of each reaction well were then read according to the amplification curve and interpreted as follows: For a specific locus of mutation in the sample, if there was amplification and the $\mathrm{Ct}$ value was $\leq 35$, the sample was considered to be positive; if there was no amplification and the $\mathrm{Ct}$ value was $>38$, the sample was negative; in cases with $35<\mathrm{Ct}$ value $\leq 38$, sample positivity was suspected and the measurement was repeated.

Statistical analysis. The SPSS 17.0 software package (SPSS Inc., Chicago, IL, USA) was used for data analysis. A percentage was used as an evaluation index of positive EGFR mutation status. Within-group differences were analyzed using the non-parametric independent t-test. Between-group differences were analyzed using the Chi-square test. $\mathrm{P}<0.05$ was considered to indicate statistically significant differences.

\section{Results}

EGFR mutation status by exon and gender. The overall positive mutation rate of EGFR was $49.02 \%$ (25/51); the mutation rate of exon 18 was $8 \%(2 / 25)$, of exon $1952 \%(13 / 25)$ and of exon $2140 \%(10 / 25)$, whereas no mutations were detected in exon 20 . The positive rate in men and women was $37.5 \%(12 / 32)$ and $68.42 \%$ (13/19), respectively. The difference between men and women was statistically significant $(\mathrm{P}<0.05$; Table I).

EGFR mutation status by histology and stage. The positive rate in adenocarcinoma and adenosquamous carcinoma patients was 55\% (22/40) and 100\% (3/3), respectively. All 7 cases of SCC and the single case of carcinoid tumor were negative for EGFR mutations. The positive rate in adenocarcinoma patients was statistically significantly higher compared with that in SCC patients $(\mathrm{P}<0.05)$ (Table II). The positive rate in patients with well-differentiated tumors was $83.33 \%(5 / 6)$, moderately differentiated tumors $46.43 \%$ (13/28) and poorly differentiated tumors $41.18 \%$ (7/17); there were no statistically significant differences observed $(\mathrm{P}>0.05)$. The positive EGFR mutation rate in patients with and in those without lymph node metastasis was $52.17 \%(12 / 23)$ and $46.43 \%$ (13/28), respectively; the difference was not statistically significant $(\mathrm{P}>0.05)$. The positive rate was $41.67 \%(5 / 12)$ and $62.5 \%(5 / 8)$ in patients with stage IA and IB disease, respectively; $66.67 \%(4 / 6)$ 
Table I. Association between gender and epidermal growth factor receptor (EGFR) gene mutation status.

\begin{tabular}{|c|c|c|c|c|}
\hline \multirow[b]{2}{*}{ Gender } & \multirow{2}{*}{$\begin{array}{c}\text { Total } \\
\text { cases } \\
(n=51)\end{array}$} & \multicolumn{2}{|c|}{ EGFR mutations } & \multirow[b]{2}{*}{ P-value } \\
\hline & & $\begin{array}{c}\text { Negative } \\
(n=26)\end{array}$ & $\begin{array}{c}\text { Positive } \\
(n=25)\end{array}$ & \\
\hline Male & 32 & 20 & 12 & 0.03271 \\
\hline Female & 19 & 6 & 13 & \\
\hline
\end{tabular}

Table II. Association between tumor histology and epidermal growth factor receptor (EGFR) gene mutation status.

\begin{tabular}{lcccc}
\hline & & \multicolumn{2}{c}{ EGFR mutations } & \\
\cline { 3 - 4 } Histology & $\begin{array}{c}\text { Toses } \\
(\mathrm{n}=51)\end{array}$ & $\begin{array}{c}\text { Negative } \\
(\mathrm{n}=26)\end{array}$ & $\begin{array}{c}\text { Positive }(\%) \\
(\mathrm{n}=25)\end{array}$ & P-value \\
\hline AdenoCa & 40 & 18 & $22(55.0)$ & 0.002 \\
SCC & 7 & 7 & $0(0.0)$ & \\
AdenoSCC & 3 & 0 & $3(100.0)$ & \\
$\begin{array}{l}\text { Carcinoid } \\
\text { tumor }\end{array}$ & 1 & 1 & $0(0.0)$ & \\
\end{tabular}

$\mathrm{Ca}$, carcinoma; SCC, squamous cell carcinoma.

and $16.67 \%(1 / 6)$ in patients with stage IIA and IIB disease, respectively; $50 \%(8 / 16)$ and $50 \%(1 / 2)$ in patients with stage IIIA and IIIB disease, respectively; and 100\% (1/1) in stage IV, without statistically significant differences $(\mathrm{P}>0.05)$.

Association between EGFR mutation status and serum tumor markers. The overall positive rate of CEA was $64.71 \%(33 / 51)$, of CYFRA 21-1 64.71\% (33/51), of CA125 27.45\% (14/51), of CA19-9 9.80\% (5/51), of SCC and ProGRP 5.88\% (3/51 each) and of AFP $2.38 \%(1 / 51)$

No significant association was observed between EGFR gene mutation and the level of preoperative serum CYFRA 21-1, CA125, CA19-9, SCC, ProGRP and AFP (all P-values >0.05). However, when the paired sample Chi-square test was used, a statistically significant association was observed between the expression of preoperative serum CEA and EGFR gene mutation status $(\mathrm{P}<0.05)$ (Table III).

\section{Discussion}

Lung cancer is one of most common malignant tumors. Although there have been significant advances in the comprehensive treatment of lung cancer, the 5-year survival rate and life quality of the patients remain very low (11). The traditional radiotherapy and chemotherapy are associated with significant toxicity and side effects due to the lack of specificity (1). Customized targeted therapy was a major breakthrough in the treatment of NSCLC patients and the EGFR gene is an important target (3). As one of the members of ErbB family, the EGFR gene is located on the short arm of chromosome 7 and
Table III. Association between serum tumor markers and epidermal growth factor receptor (EGFR) gene mutation status.

\begin{tabular}{|c|c|c|c|}
\hline \multirow[b]{2}{*}{ Markers } & \multicolumn{2}{|c|}{ EGFR mutations } & \multirow[b]{2}{*}{ P-value } \\
\hline & $\begin{array}{c}\text { Positive } \\
(n=25)\end{array}$ & $\begin{array}{c}\text { Negative } \\
(n=26)\end{array}$ & \\
\hline CYFRA 21-1 & & & 0.346 \\
\hline Positive & 15 & 18 & \\
\hline Negative & 10 & 8 & \\
\hline CA19-9 & & & 1.000 \\
\hline Positive & 2 & 3 & \\
\hline Negative & 23 & 23 & \\
\hline CA125 & & & 1.000 \\
\hline Positive & 7 & 7 & \\
\hline Negative & 18 & 19 & \\
\hline SCC antigen & & & 0.610 \\
\hline Positive & 2 & 1 & \\
\hline Negative & 23 & 25 & \\
\hline CEA & & & 0.025 \\
\hline Positive & 20 & 13 & \\
\hline Negative & 5 & 13 & \\
\hline AFP & & & 0.510 \\
\hline Positive & 0 & 1 & \\
\hline Negative & 25 & 25 & \\
\hline ProGRP & & & 0.235 \\
\hline Positive & 0 & 3 & \\
\hline Negative & 25 & 23 & \\
\hline
\end{tabular}

CYFRA 21-1, cytokeratin-19-fragment; CA19-9, carbohydrate antigen 19-9; CA125, carbohydrate antigen 125; SCC, squamous cell carcinoma; CEA, carcinoembryonic antigen; AFP, $\alpha$-fetoprotein; ProGRP, progastrin-releasing peptide.

consists of 28 exons (2). EGFR is a transmembrane glycoprotein receptor with tyrosine kinase activity and is highly expressed in $45-70 \%$ of NSCLC patients $(12,13)$. EGFR acts on the cell signal transduction pathway, promotes the differentiation and proliferation of tumor cells, promotes tumor angiogenesis and metastasis and inhibits apoptosis (14-16). Multiple studies have proven that customized therapy significantly improved the survival rate and life quality of EGFR-positive lung cancer patients $(17,18)$. With the improved understanding of the process of tumor pathogenesis and of the effects of EGFR gene mutation on tumor characteristics, targeted therapy has become increasingly more important, perfected and normalized (15). Molecular-targeted therapy using EGFR as the target is currently used in the clinical setting for the treatment of lung cancer $(19,20)$.

It was reported that, in China, lung cancer patients mainly exhibit EGFR mutations in exons 19 and 21, accounting for 54.5 and $40.3 \%$ of the total mutation rate, respectively, while mutations are rare in exons 18 and 20 (15). In this study of 51 NSCLC patients, the mutation rate in exons 19 and 21 was 52 and $40 \%$, respectively, while that in exon 18 was only $8 \%$, which is consistent with the majority of the literature reports $(2,14,16)$. 
According to Wu et al (21) the mutation rate of the EGFR gene in women and men was 42.9 and $23.1 \%$, respectively. In this study, the mutation rate in female patients was $68.42 \%$, which was higher compared with that in male patients $(37.5 \%)$, with a statistically significant difference $(\mathrm{P}<0.05)(10,18,19,21)$. The degree of differentiation of the tumor was an important index for assessing malignant potential and prognosis. According to this study, the mutation rate in patients with well-differentiated tumors was $83.33 \%$, in patients with moderately differentiated tumors $46.43 \%$ and in patients with poorly differentiated tumors $41.18 \%$, which was inconsistent with previous findings (3). This inconsistency may be attributed to the lack of well-differentiated cases in this study; therefore a larger sample size is required to confirm this result $(11,22)$. In addition, no statistical association was observed between lymph node metastasis, TNM stage and EGFR mutation $(P>0.05)$, which was in agreement with the findings of Li et al (1).

According to Xu et al (23) and Shoji et al (24), the positive mutation rate of the EGFR gene was found to be increased when the level of serum CEA was positive preoperatively. In this study, of the 51 cases, 33 were positive for CEA, including $20 \mathrm{EFGR}$-positive cases, with a mutation rate of EGFR for CEA-positive patients of $60.6 \%$ (20/33). According to the statistical analysis, there was a significant association between EGFR mutation and the level of preoperative serum CEA $(\mathrm{P}<0.05)$. Therefore, the level of preoperative CEA expression is likely to be an independent predictor of EGFR mutations.

In this study, the mutation rate of EGFR in female lung adenocarcinoma patients in the Xinjiang region was $\sim 70 \%$ and the high estimated level of CEA was associated with EGFR mutation status. It remains to be elucidated whether the determination of serum CEA can replace EGFR testing for NSCLC patients by increasing sample size.

\section{Acknowledgements}

This study was supported by Returned Overseas Students to Science and Technology Activities Fund (2012-111) and the National Natural Science Foundation of China (no. 30960383). The authors would also like to express their gratitude to the laboratory staff for helping with the measurement of the tumor markers and the Pathology Department staff for assisting in the determination of EGFR gene mutation.

\section{References}

1. Li MN, Li X, He ZC and Zhang ZH: Association between gene mutations of epidermal growth factor receptor and clinicopathological characteristics of non-small cell lung cancers. J Clin Exp Pathol 29: 402-405, 2013

2. da Cunha Santos G, Shepherd FA and Tsao MS: EGFR mutations and lung cancer. Annu Rev Pathol 6: 49-69, 2011.

3. Huang GH, Du J, Hou XH, et al: A clinical pathology study between the different differentiation of non-small cell lung cancer (NSCLC) and the mutation of EGFR gene. Mol Diagn Ther 6: 97-100, 2014.

4. Li H, Pan Y, Li Y, et al: Frequency of well-identified oncogenic driver mutations in lung adenocarcinoma of smokers varies with histological subtypes and graduated smoking dose. Lung Cancer 79: 8-13, 2013.
5. Boch C, Kollmeier J, Roth A, Stephan-Falkenau S, Misch D, Grüning W, Bauer TT and Mairinger T: The frequency of EGFR and KRAS mutations in non-small cell lung cancer (NSCLC): Routine screening data for central Europe from a cohort study. BMJ Open 3: 1-6, 2013.

6. Liu N, Zhang K, Yan SX, et al: EGFR mutations are closely associated with gefitinib response in non-small cell lung cancer patients. Modern Oncology 21: 330-333, 2013.

7. Zhang YS, He YY, Li XF, et al: Clinical analysis of factors influencing EGFR mutation status in patients with non-small cell lung cancer. Tumor 34: 147-152, 2014.

8. Yu H, Huang X, Zhu Z, Hu Y, Ou W, Zhang L and Zhou N: Significance of combined detection of LunX mRNA and tumor markers in diagnosis of lung carcinoma. Chin J Cancer Res 26: 89-94, 2014.

9. Wang WJ, Tao Z, Gu W and Sun LH: Clinical observations on the association between diagnosis of lung cancer and serum tumor markers in combination. Asian Pac J Cancer Prev 14: 4369-4371, 2013

10. Cedrés S, Nuñez I, Longo M, Martinez P, Checa E, Torrejón D and Felip E: Serum tumor markers CEA, CYFRA21-1, and CA-125 are associated with worse prognosis in advanced non-small-cell lung cancer (NSCLC). Clin Lung Cancer 12: 172-179, 2011.

11. Zhou JX, Yang H, Deng Q, et al: Oncogenic driver mutations in patients with non-small-cell lung cancer at various clinical stages. Ann Oncol 24: 1319-1325, 2013.

12. Huang Q and Li DQ: Epidermal growth factor receptor and alveolar epithelial atypical adenomatous hyperplasia. Int J Pathol Clin Med 32: 84-87, 2012.

13. Schneider CP, Heigener D, Schott-von-Römer K, et al: Epidermal growth factor receptor-related tumor markers and clinical outcomes with erlotinib in non-small cell lung cancer: An analysis of patients from German centers in the TRUST study. J Thorac Oncol 3: 1446-1453, 2008.

14. Wang X, Shi SS, Ma HH, et al: Respective analysis of EGFR mutations in non-small cell lung cancer. Mil Med J Southeast China 14: 387-389, 2012.

15. Zhao J, Zhu Y, Zhang L, Yu YW and Zheng JM: Detection of epidermal growth factor receptor gene mutations and its clinical significance in non-small cell lung cancers. Chin J Pathol 40: 671-674, 2011 (In Chinese)

16. Sriuranpong V, Chantranuwat C, Huapai N, Chalermchai T, Leungtaweeboon K, Lertsanguansinchai P, Voravud N and Mutirangura A: High frequency of mutation of epidermal growth factor receptor in lung adenocarcinoma in Thailand. Cancer Lett 239: 292-297, 2006.

17. Kobayashi S, Canepa HM, Bailey AS, Nakayama S, Yamaguchi N, Goldstein MA, Huberman MS and Costa DB: Compound EGFR mutations and response to EGFR tyrosine kinase inhibitors. J Thorac Oncol 8: 45-51, 2013.

18. Hata A, Yoshioka H, Fujita S, et al: Complex mutations in the epidermal growth factor receptor gene in non-small cell lung cancer. J Thorac Oncol 5: 1524-1528, 2010.

19. van Zandwijk N, Mathy A, Boerrigter L, Ruijter H, Tielen I, de Jong D, Baas P, Burgers $S$ and Nederlof P: EGFR and KRAS mutations as criteria for treatment with tyrosine kinase inhibitors: Retro- and prospective observations in non-small-cell lung cancer. Ann Oncol 18: 99-103, 2007.

20. Boldrini L, Alì G, Gisfredi S, et al: Epidermal growth factor receptor and K-RAS mutations in 411 lung adenocarcinoma: A population-based prospective study. Oncol Rep 22: 683-691, 2009.

21. Wu YL, Zhong WZ, Li LY, et al: Epidermal growth factor receptor mutations and their correlation with gefitinib therapy in patients with non-small cell lung cancer: A meta-analysis based on updated individual patient data from six medical centers in mainland China. J Thorac Oncol 2: 430-439, 2007.

22. Zhu CQ, da Cunha Santos G, Ding K, et al; National Cancer Institute of Canada Clinical Trials Group Study BR.21: Role of KRAS and EGFR as biomarkers of response to erlotinib in National Cancer Institute of Canada Clinical Trials Group Study BR.21. J Clin Oncol 26: 4268-4275, 2008.

23. Xu L, Zheng MF, Zhang J, Zhu XF, Chen R, Lu R, Wo B and Chen J: EGFR Mutations in correlation with the tumor markers in NSCLC patients. J Med Res 40: 79-81, 2011.

24. Shoji F, Yoshino I, Yano T, Kometani T, Ohba T, Kouso H, Takenaka T, Miura N, Okazaki H and Maehara Y: Serum carcinoembryonic antigen level is associated with epidermal growth factor receptor mutations in recurrent lung adenocarcinomas. Cancer 110: 2793-2798, 2007. 